\section{Didiana Prata}

Orientadora Giselle Beiguelman
CUPAR, MEDIAR E RESSIGNIFICAR A IMAGEM DA CIDADE

\title{
RESUMO
}

A inauguração da ciclovia Av. Paulista e o fechamento das pistas de veículos, aos domingos, para uso exclusivo do pedestre transformaram a avenida ícone da cidade em mais um espaço ressignificado pelo seu uso temporário. A partir desse exemplo de acontecimento coletivo, relacionaremos a experiência do pedestre ou ciclista e a produção de imagens da paisagem urbana feita com dispositivos móveis, as câmeras de celular. 0 enfoque principal será verificar como se dá a apreensão estética das coisas urbanas, por meio da produção, mediação e veiculação de imagens nas redes sociais - especificamente no Instagram - e em que medida a superprodução de imagens, motivadas a partir de um evento, e a estetização do cotidiano possibilitam a produção de novas poéticas e novos vínculos com a cidade.

Palavras-chave

Imagem mobile. Cidade participativa. Instagram. Paisagem urbana. 


\section{OCCUPYING, MEDIATING AND RESIGNIFYING THE CITY'S IMAGE}

\section{ABSTRACT}

The opening of the bike path on Avenida Paulista and the closing of vehicle lanes on Sundays for exclusive pedestrian use transformed the city's iconic avenue into another space reframed for its temporary use. From this example of collective event, we will relate the experience of pedestrians or cyclists with the production of urban landscape images made with mobile devices, the mobile phone cameras.

The main focus will be to understand how the aesthetic absorption of urban things comes through, via production, mediation and placement of images on social networks - specifically on Instagram - and to what extent overproduction of event driven pictures, and the aestheticsoriented day-to-day routine allow for the production of new poetry and new bonds with the city.

\section{KEYWORDS}

Mobile image. Participative city. Instagram. Urban landscape. 
10 Instagram funciona como rede social e aplicativo com filtros e plug-ins para edição fotográfica, disponível para smartphones IOS e Android. 0 número de usuários no mundo chega a mais de 300 milhões. 0 número de compartilhamento "shares" é de 60 milhões de fotos e vídeos por dia, com 1,1 milhão de curtidas por minuto. 0 aplicativo tem sua funcionalidade traduzida em 25 idiomas, e o Brasil é o quinto país com maior número de usuários. Disponível em: <http:/ /www.instagram.com>. Acesso em: outubro 2015

2 Os assuntos referentes à produção de linguagem com imagem mobile foram extraídos e adaptados da dissertação de mestrado Imageria e poéticas de representação da paisagem urbana nas redes (PRATA, 2016), sob orientação de Giselle Beiguelman. Disponível em: <http://www.teses.usp.br/teses/ disponiveis/16/16136/tde16022017-095419/pt-br.php>.
O domingo de 28 de junho de 2015 amanheceu com o céu limpo, como um típico dia de inverno. Era um convite para o paulistano sair à rua e divertir-se ao ar livre. Naquela manhã, inaugurava-se simultaneamente a ciclovia da Av. Paulista e a abertura desta via para o uso exclusivo de lazer aos domingos e feriados. 0 projeto de implantação de ciclovias virou o símbolo da gestão Haddad (2012-2016) como exemplo de uma nova política urbana, em que se priorizam a mobilidade e a coletividade.

A abertura da avenida faz parte do projeto "Ruas Abertas", implantado pelo exprefeito em 29 vias em diferentes regiões de São Paulo. Representou uma mudança significativa relacionada ao uso do espaço urbano e à qualidade de vida do cidadão paulistano, que passou a contar com a rua como um lugar destinado a atividades esportivas e culturais e a trocas sociais e afetivas. Especificamente na Av. Paulista, o "Ruas Abertas" teve um impacto significativo e simbólico, tornando ainda mais visível a vocação da avenida como o lugar de disputas políticas e de diversas manifestações culturais e artísticas.

A multiplicidade de usos e eventos que acontecem em um espaço topologicamente e historicamente singular, ladeado por construções icônicas, a ciclovia da Paulista e o fechamento da avenida induziram a uma ressignificação desse lugar. Aos domingos, os edifícios e seus espaços internos, externos e intersticiais, como o vão do MASP e o térreo do Conjunto Nacional - para citar apenas dois icônicos edifícios -, se fundem com as vias, transformadas em espaço público, um parque linear asfaltado que pode ser apreciado a partir de uma outra perspectiva: a do lazer e do ponto de vista do ciclista e do pedestre.

Nesse contexto, no qual a arquitetura e a riqueza patrimonial da cidade se desvelam para o pedestre, é que se dá a construção de uma nova experiência estética do cidadão com a cidade, mediada por uma intensa produção de imagens, realizada com dispositivos móveis, as câmeras celulares. Imagens, em suma, produzidas na sua deriva urbana.

Como se dá a apreensão estética das coisas urbanas por meio das imagens produzidas, mediadas e veiculadas nas redes sociais, especificamente no Instagram ${ }^{1}$. Em que medida a superprodução de imagens, motivadas a partir de um evento, e a estetização do cotidiano possibilitam um novo olhar sobre o lugar onde vivemos? Em outras palavras, como as camadas da metrópole tornam-se legíveis pelos cidadãos munidos de seus celulares, mediando fragmentos da cidade em tempo real?

Para compreender a singularidade dessas narrativas construídas com imagens mobile - imagens captadas "em movimento", potencializadas pelos recursos tecnológicos das câmeras e dos aplicativos dos aparelhos celulares, nos quais são produzidas, mediadas e veiculadas - vamos explorar as intersecções entre os territórios geográficos (o espaço urbano) e os territórios informacionais (o ciberespaço), nos quais essa produção de linguagem está inserida².

A singularidade da linguagem imagética em pauta está imbricada com 0 movimento do corpo, do olho e da câmera "como um terceiro olho na palma da mão" (BEIGUELMAN; LA FERLA, 2011, p. 251). Envolve a comunicação em tempo real das redes e a contaminação da esfera individual pela coletiva. 0 uso desse dispositivo de produção de linguagem dá visibilidade ao cotidiano, ao 
3 Utilizamos o termo "imagem mobile", em vez da denominação corrente "fotografia mobile", pois assumimos não só suas características metamórficas (dentro do novo regime de imageria de Rancière), mas também o caráter móvel, tecnológico e numérico dessa imagem em permanente deslocamento. Esse assunto é desenvolvido a partir de paradigmas teóricos de Edmond Couchot em Prata (2016, p.30; COUCHOT, 2003). ordinário, e potencializa movimentos de ativismo social e cultural, conecta o cidadão e convida-o a relacionar-se de outra maneira com o ciberespaço e com a paisagem que o cerca.

Constatamos o quanto as raízes dessa nova prática estética estão imbricadas com as manifestações da cultura urbana contemporânea e com os movimentos político-sociais de um mundo cada vez mais globalizado, conectado em redes informacionais. Assumimos o viés tecnológico, cultural e artístico dessa prática para investigarmos as relações entre representação e subjetivação do espaço a partir dessas narrativas fragmentadas, diluídas no fluxo midiático das redes.

\section{EstetiZAÇÃO DO COTIDIANO}

Vivemos numa época de saturação de imagens, produzidas e mediadas por diversos meios e redes. Os dispositivos móveis, especificamente o celular, passaram a ser uma extensão natural, uma prótese tecnológica do corpo do homem contemporâneo.

No dia da inauguração da ciclovia da Paulista, cerca de 2.000 ciclistas passaram pela avenida. A grande maioria estava munida de celulares, com suas câmeras e dispositivos de tecnologia 3G ou 4G. Não bastava vivenciar a experiência; era preciso documentá-la, mediá-la e compartilhá-la nas redes. A presença simultânea do paulistano no evento e nas redes sociais, como produtor e mediador de registros imagéticos daquele instante, ilustra a condição atual do homem contemporâneo. É dentro desse contexto que está inserido o autor, o artista e também editor e produtor das imagens mobile ${ }^{3}$.

O viés multicultural, tecnológico e estetizante dessa prática cotidiana e urbana de se comunicar por imagens mediadas pode ser mais bem compreendido a partir de Bourriaud (2011). O autor vai buscar na ciência, especificamente na botânica, a imagem de raiz para desenvolver a teoria da estética radicante. Parte das raízes culturais (o modernismo) para conceituar os novos enraizamentos multiculturais da arte contemporânea. Ele aposta que "os criadores de hoje baseiam-se em uma arte RADICANTE - epíteto que designa um organismo capaz de fazer brotar suas próprias raízes e de agregá-las à medida que vai avançando" (BOURRIAUD, 2011, p.20).

A estética radicante contextualiza as novas representações de linguagem, como as narrativas produzidas com imagens mobile. É uma nova poética empoderada pelos repertórios culturais, sociais e de consumo, e pode ser produzida e consumida por qualquer cidadão. Ou seja, o homem comum produz, media e veicula sua "arte" de forma independente e instantânea, livre de qualquer curadoria e institucionalização.

Estamos na era da representação artística produzida na multiplicidade, de novos formatos de expressões culturais e artísticas, mediadas e veiculadas por textos e imagens. A figura do DJ, usada por Bourriaud, descreve esse novo produtor de linguagem e artista que se apropria da produção coletiva e a agrega à sua. Ele usa a lógica do sample, do remix, do ready-made e do deslocamento do significado. "O imaginário contemporâneo está desterritorializado, à semelhança da produção global [...]", diz Bourriaud (2011, p.176). 


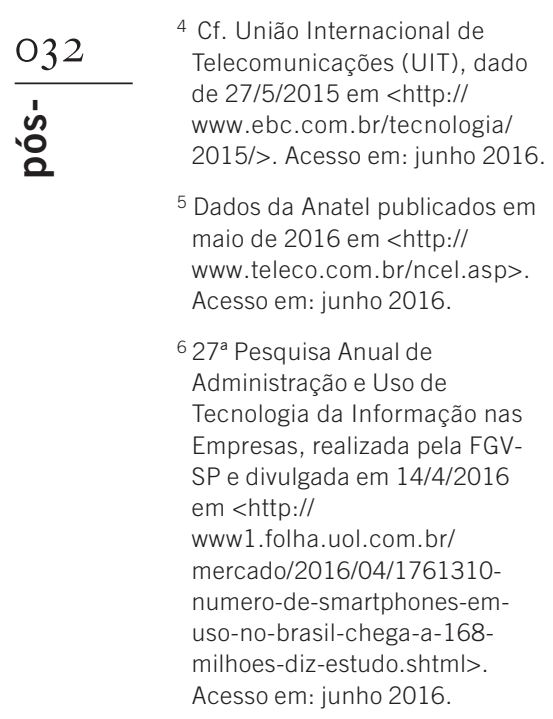

4 Cf. União Internacional de elecomunicações (UIT), dado 2015/>. Acesso em: junho 2016 www.teleco.com.br/ncel.asp > em: junho 2016 ecnologia da Informação nas Presas, realizada pela FGVAcesso em: junho 2016.
A referência à imagem do rizoma de Deleuze e Guattari em Mil platôs: capitalismo e esquizofrenia (1996), em oposição à verticalidade da árvore, é uma citação de Bourriaud que também ilustra a arte radicante e aplica-se perfeitamente aos dias de hoje, em tempos de redes fluidas, não hierárquicas, de geografias celulares.

Inserido nesse contexto multicultural e desterritorializado, o cidadão globalizado está conectado vinte e quatro horas por dia a um dispositivo móvel, o gadget mais vendido e explorado pela indústria das telecomunicações e de tecnologia em todo o mundo. São mais de 7 bilhões de celulares em todo o mundo ${ }^{4}$ (correspondendo a quase $100 \%$ da população mundial). 0 Brasil figura em quarto lugar na lista de países com celulares em uso, depois da China, Índia e EUA: são 255,2 milhões de aparelhos no país ${ }^{5}$, o equivalente à densidade de 1,2 celular por habitante.

Os modelos smartphones correspondem a $65 \%$ do total de celulares no Brasil (168 milhões). Esses dispositivos com câmeras e aplicativos de pré e pósedição, vinculados às redes sociais, abrem novos paradigmas para essa cultura do efêmero. Nunca se fotografou tanto, e no meio dessa imageria há indícios de uma nova corrente artística, de uma produção de linguagem condicionada ao deslocamento e às publicações fragmentadas nas redes.

Importa-nos compreender como a cidade de São Paulo é representada pelas narrativas do cotidiano produzidas com dispositivos móveis pelo cidadão comum e por artistas amadores ou não. E como esse fenômeno de tradução revela uma leitura semântica do espaço urbano.

A produção imagética das redes, a partir do prisma da "estética radicante", é entendida como manifestação de linguagem e estabelece uma relação entre produção artística, deslocamento e camadas narrativas "traduzidas" e dispostas, em tempo real, no aplicativo Instagram. Ao nos determos nas imagens editadas para este artigo (uma pequena amostra da imageria urbana da dissertação de mestrado da autora [PRATA, 2016]), vemos como a imagem hoje pode representar uma comunicação narcísica, a estetização do cotidiano e também uma manifestação poética do artista radicante, em que há acúmulo de referências, multiplicidades, apropriações, sem hierarquização dos elementos formais.

A figura do nômade contemporâneo também ilustra o fotógrafo, ou melhor, o produtor de imagem com dispositivos móveis. Este se instala momentaneamente nos lugares por onde passa, empresta-Ihes novas características temporárias inerentes ao movimento, à passagem. A noção de tempo-espaço passa a reger o movimento desse artista contemporâneo, que não se prende a um circuito fechado, que converte a geografia em psicogeografias e ensaios imagéticos. Veremos a seguir.

Descrevemos a Av. Paulista aos domingos para tentar aproximar as características formais do lugar às narrativas imagéticas produzidas pelos cidadãos. São imagens legendadas, indexadas como \#ciclovianapaulista ou por outros tagueamentos, que passam a compor diversas metanarrativas, a partir das várias possibilidades de leitura das imagens no Instagram (por "\#" temático, por autor, pelo pin de georreferenciação). São ensaios imagéticos coletivos que merecem ser investigados pela sua importância na ressignificação do uso e da representação poética do espaço urbano. 


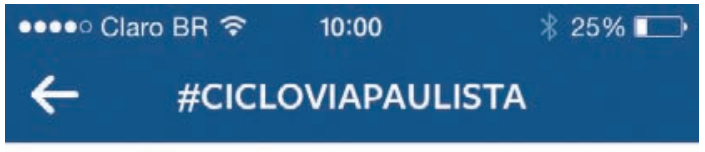

MOST RECENT
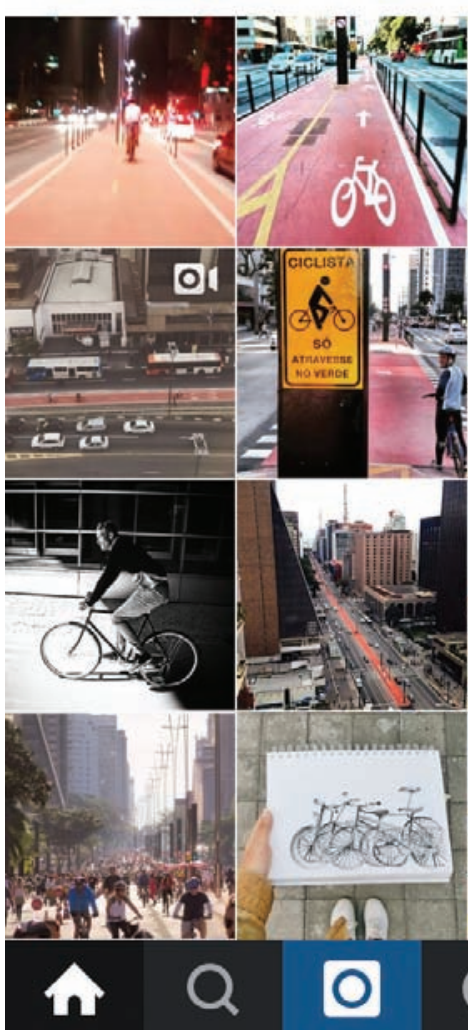

Q

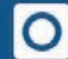

Figura 1. Captura de tela do aplicativo Instagram no dia da inauguração da ciclovia da Paulista.

No período de doze horas, foram publicadas 1.631 imagens com a hashtag \#cicloviapaulista. Fonte: Instagram

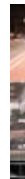
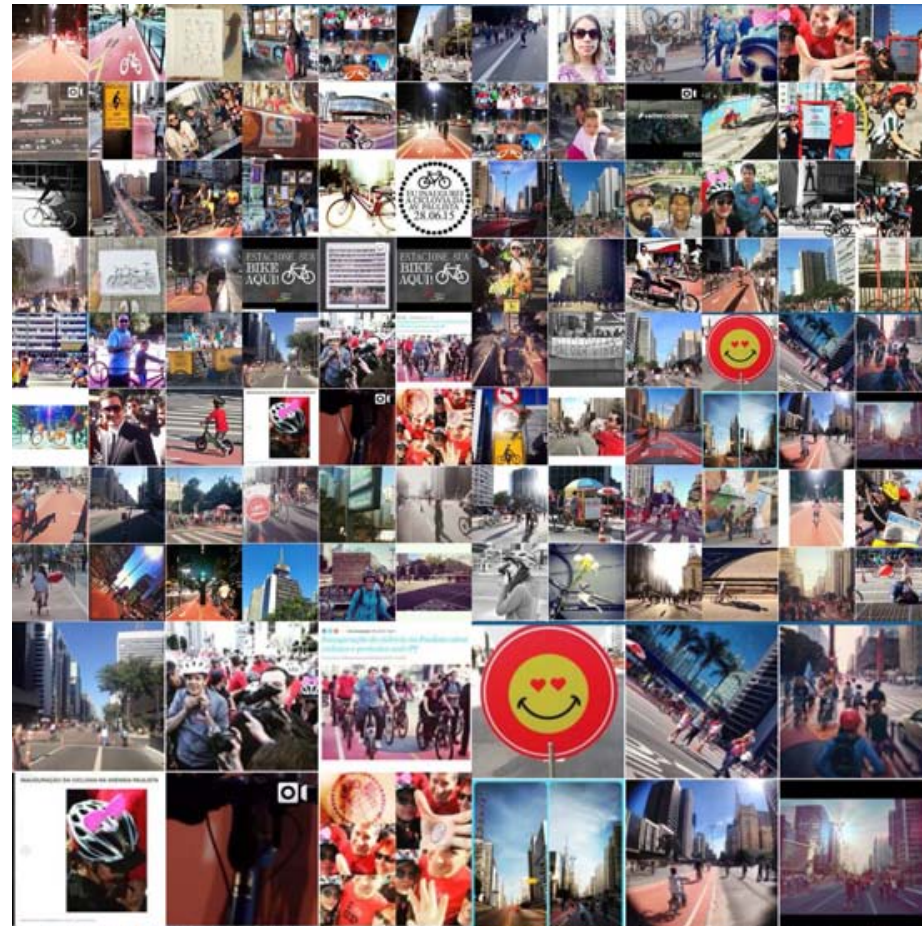

의

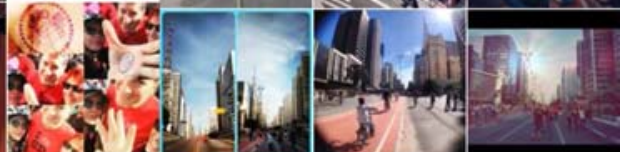

pós$\mid \begin{aligned} & 0 \\ & \omega\end{aligned}$

Em um primeiro olhar, é inegável o viés afetivo, lúdico e banalizado dessas mensagens imagéticas. Visualizadas em conjunto, as milhares de imagens apontam, sob o ponto de vista formal, para a aparente negação dos elementos sensíveis de composição e iluminação inerentes ao trabalho artístico. 0 conjunto de imagens de \#cicloviapaulista reforça a participação social estetizada de um acontecimento efêmero e fragmentado. A possibilidade de uso dos filtros disponíveis nos aplicativos também contribui para a mediação e edição da foto, ampliando as possibilidades estetizantes do jogo. É a imagem como mensagem, muitas vezes desprovida de sintaxe visual. É a imagem direta, como carimbo "eu fui", "estive lá". O número de "autorretratos", denominados selfies nas redes sociais, evidencia esse padrão de comportamento de estetização do cotidiano e levanta questões de pertencimento, identificação e ideação narcísica de uma geração que vive em um contexto no qual há uma interpenetração constante entre os ambientes on-line e off-line. 
O usuário da câmera de celular faz parte de um jogo de representação de afetos estetizados e utiliza-se da possibilidade de produção e reprodução dessa imagem como um artista anônimo.

Ao olhar essa diversidade de fotos, organizada pela busca algorítmica \#cicloviapaulista, percebemos várias camadas narrativas. No meio de 1.631 imagens (postadas em apenas doze horas desde a inauguração da ciclovia), há a possibilidade de outras edições, renomeadas com diferentes hashtags. As imagens se reagrupam em diferentes narrativas, apresentadas em galerias virtuais temáticas.

Parece-me importante destacar justamente a potencialidade dessa imagem produzida no ambiente urbano, em que a paisagem é objeto e muitas vezes suporte. Há uma nova linguagem poética, fruto da vivência e percepção sobre o construído, o existente, as coisas urbanas. Essas imagens ganham força na medida em que se apresentam em forma de narrativas cotidianas. São narrativas que transcendem o viés comunicacional e nasceram da imbricaçâo da vivência do homem contemporâneo em espaços de fluxos, na rua e no ciberespaço. São experiências sensoriais e estéticas.

\section{SuPERPRODUÇÃO DE IMAGENS E PRODUÇÃO DE LINGUAGEM}

A superprodução de imagens não é um dado novo na história. Em O destino das imagens, Rancière (2013) conta que a proliferação de imagens como narrativa cotidiana tem sua origem no século XIX, com o advento das técnicas reprodutivas, incluindo a fotografia, e a descentralização das artes e do poder, antes confinados à Igreja e aos impérios e reinados. Inicia-se um período de troca entre as imagens da arte e a comercialização de novos produtos, de reproduções de "imageria coletiva" dedicada a contar uma história de uma sociedade por meios que permitem às pessoas ver-se e rir-se de si mesmas. Surgem várias publicações populares, como o Magazin Pittoresque, em que o texto e as imagens, editadas em forma de vinhetas e historinhas, espelhavam a sociedade de uma época.

A imageria, impressa ou digital, também está vinculada ao colecionismo, um elemento intrínseco à história da arte, da ciência e da tecnologia e à história da reprodutibilidade técnica. Destacamos como exemplo de imageria o Atlas Mnemosyne, composto por Aby Warburg entre 1924 e 1929 - referência fundamental para entendermos as narrativas visuais com imagerias contemporâneas.

Nos dias de hoje, a imageria está associada a imagens digitais que circulam nas redes. Elas são publicadas em galerias virtuais, podem estar vinculadas a coleções institucionais ou privadas, ou podem ser fruto da produção individual de um artista que se apropria da imageria como matéria-prima para sua produção artística. As "coleções" de imageria produzidas de forma individual ou coletiva e disponibilizadas especificamente no Instagram, para acesso de qualquer um, estão exemplificadas aqui por meio da imageria temática da Av. Paulista. 
Vimos com Bourriaud como o contexto multicultural atual propicia a produção de diversas manifestações estéticas do artista amador, do homem contemporâneo. Aprofundaremos a questão da produção e veiculação de imageria pelo artista anônimo a partir de Rancière, para quem vivemos numa época de extrema estetização do cotidiano, em que a partilha (divisão, compartilhamento) do sensível significa a partilha de um sentimento particular em relação ao sentimento ou acontecimento comum. É um partilhar de fragmentos de espaços e tempos simultâneos (RANCIÈRE, 2005, p.15).

Assim como Bourriaud, Rancière afirma que é justamente no terreno estético que se trava hoje a discussão política, a generalização do espetáculo e a multiplicação dos discursos. Estamos constantemente dando visibilidade às relações sociais, culturais e políticas e, portanto, produzindo no campo da estética nossa manifestação discursiva. 0 autor propõe um novo regime estético das artes no qual "a revolução estética é antes de tudo a glória do qualquer um” (RANCIÈRE, 2005, p.48). Esse princípio confere visibilidade ao anônimo, que é capaz de produzir arte e também conferir beleza a outros modos de representação, destituídos de sistemas e hierarquias de gêneros de representação das artes visuais. Nesse novo regime estético, o banal torna-se belo como rastro do verdadeiro. A legitimidade da narrativa passa pela ficção, pela representação do belo, para que se possa pensar a história ou o acontecimento. Assim, discutem-se os arranjos entre os signos do real e das imagens, as relações do que se vê e o que se diz, entre o que se faz e o que se pode fazer, por meio da linguagem.

Para Rancière, dar visibilidade é uma operação política. A partir desse novo regime estético ao qual as imagens mobile pertencem, podemos dizer que a grande questão passa a ser como podemos medir o nosso poder por meio da nossa visibilidade. É um problema pertinente à complexidade das operações envolvidas nas publicações de imagens e mensagens nas redes sociais. Não só pela articulação entre arte, política e estética, mas sobretudo pela heterogeneidade da qualidade do que é publicado e distribuído. Os artistas anônimos têm posse da imagem, mas esta nem sempre está conectada a uma mensagem significativa. É como se a hierarquia de representação fosse quebrada por uma superprodução de imagens mudas, sem "discurso" individual. Como se a visibilidade dessas imagens dependesse de um outro sistema de representação para torná-las visíveis.

A experiência de novas formas de representação estética de imagens digitais nas redes se dá de diferentes formas. Vemos a realidade cotidiana autenticada por imagens que seguem diversos estilos, de acordo com o repertório de cada um. São imagens produzidas e utilizadas, na maioria das vezes, como emissoras de experiências hedonistas ou de manifestações poéticas de diferentes naturezas. Veremos nos exemplos a seguir uma das várias possibilidades de edição de imagens no Instagram, nos quais a legenda, ou melhor, o tagueamento do "\#" comum, organiza um discurso de imageria coletiva. 


\section{IMAGERIA: NOVAS POTENCIALIDADES E FUNÇÕES DA IMAGEM}

Rancière insere a linguagem da imagem atual, do fluxo das redes e das mídias no conceito de um novo "regime de imagéité": "As imagens são operações: relações entre um todo e as partes, entre uma visibilidade e uma potência de significação e de afeto que Ihe é associada, entre as expectativas e aquilo que vem preenchê-las." (RANCIÈRE, 2013, p.11-12).

Para o autor, a natureza intrínseca das imagens, em qualquer meio, é a mesma. O que muda é sua performance na tela do cinema, na tela da televisão, na tela do celular. Os afetos que elas suscitam são inerentes à sua natureza e não ao meio tecnológico/performático em que são distribuídas. Segundo Rancière, é importante reconhecer as propriedades estéticas das imagens de arte nas transformações contemporâneas do lugar que elas ocupam. Ele está preocupado com dois tipos de jogos: o que se dá entre o real e a imagem produzida à semelhança; e aquele que consiste em operar a alteração dessa semelhança. Nesse último jogo de operações, o autor identifica que as imagens de arte, enquanto tais, são dessemelhanças e que o regime comum da imagem é aquele que põe em cena uma relação do dizível com o visível (RANCIÈRE, 2013, p.15-17).

Rancière introduz três formas de imagéité - a imagem nua, a ostensiva e a metamórfica - e levanta três poderes vinculados à imagem: o poder de mostrar, o poder de significar e o poder de dar testemunho da história. Podemos relacionar a forma metamórfica às operações de linguagens associadas às imagens produzidas com câmeras de celulares.

Segundo essa lógica, é impossível circunscrever uma esfera específica de presença que isolaria as operações e os produtos da arte das formas de circulação da imageria social e comercial, e das operações de interpretação dessa imageria. (RANCIÈRE, 2013, p.34)

Vale destacar que Rancière utiliza o termo imagérie para tratar das imagens inseridas no contexto desse novo regime de imagens. Traduzimos e adotamos a palavra como "imageria", primeiramente por ela revelar a natureza da imagem mobile, uma imagem que pertence a esse novo regime de imagens das redes, a essa imageria. Em segundo lugar, pela associação direta que fazemos de "imageria" com "imaginário", revelando a natureza onírica e subjetiva das narrativas visuais das redes.

Assim, o papel da imageria produzida e circulada nas redes pode ser associado ao papel da imagem metamórfica conceituado por Rancière: os novos dispositivos transferem novas funções às imagens, que passam a assumir papéis potencializados inerentes ao lugar midiático onde a imagem circula. Esses dispositivos podem transferir à imagem tarefas relacionadas à crítica e curadoria dessa própria imagem, em um jogo narrativo inédito.

Ao olhar a diversidade de fotos organizada pela busca por \#cicloviapaulista vemos várias camadas narrativas. Esses agrupamentos de imagens fragmentadas e desconectadas, quando reunidos sob o mesmo "\#", apresentam os elementos da imagérié e do jogo de imagens e de narrativas metamórficas, descritos por Rancière. A imagem metamórfica conecta-se a outros tipos de imagens para interromper o fluxo midiático, dando visibilidade 
a uma narrativa. Seguindo esse raciocínio, a estética de tal imagem passa também a ter uma natureza dupla. Ela faz parte de uma narrativa singular, contextualizada por seu autor, participante de um jogo estetizante de produção de linguagem, e, simultaneamente, pertence à imageria de imagens produzidas como manifestações socioculturais e políticas, suscetíveis à invisibilidade por estarem no fluxo midiático.

\section{Produção de LINGUAgem}

\section{Redes informacionais}

A infraestrutura para a mobilidade urbana e consequente uso dos dispositivos móveis nas estratégias artísticas e comunicacionais depende fundamentalmente da rede de telefonia celular, uma malha invisível e difusa. Esse tema é tratado por Marcus Bastos em Mapeamento incompleto de algumas geografias celulares (2010). O autor descreve a rede como um espaço de fluxo de dois sentidos: de deslocamento de informação e de conexões em deslocamento, configurando um regime no qual se torna imperativo pensar nos limites do visível e do invisível. Essa rede de celulares, segundo Bastos,
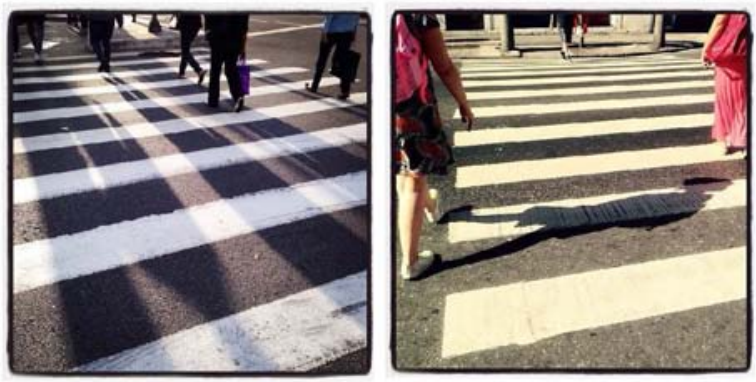

Figura 3. Ensaios editados a partir das buscas por \#cicloviapaulista, \#avenidapaulista e pin de geolocalização "av. Paulista". Imagens de @everball, @danyzappa e @miriamhomemdemelo, capturadas do aplicativo Iconosquare. Fonte: Instagram. Edição da autora
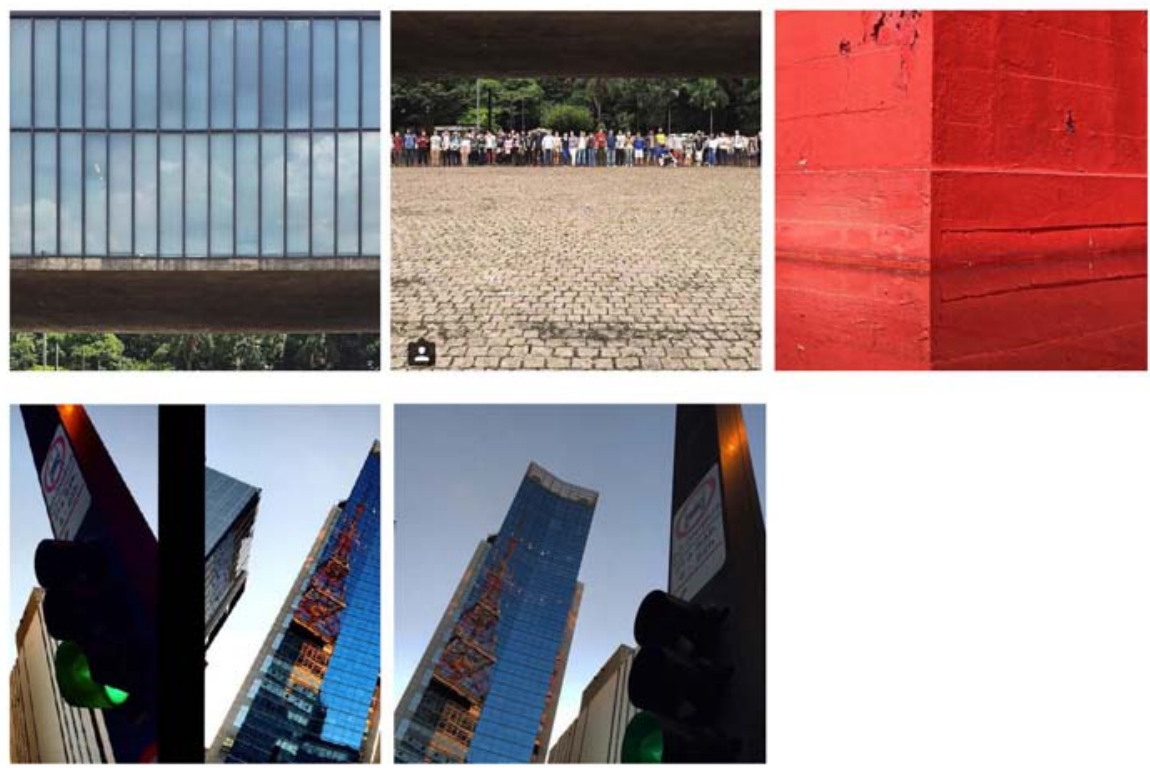
apresenta uma estrutura multiplicadora de modelo distribuído de difusão (não há mais uma rede difusora centralizada como a TV ou o rádio).

As redes informacionais funcionam em cadeias que se reverberam, mimetizam aspectos dos organismos vivos, tecem uma malha invisível e fluida sobre a geografia física. Bastos também descreve como mimética a relação do aparelho celular com o corpo, levantando a questão da cibernetização do corpo. Do vestir-se com a rede, um grande organismo composto por conexões e espaços (BASTOS, 2010).

O uso dos dispositivos móveis está intrinsecamente relacionado ao espaço, seja no âmbito do uso do próprio dispositivo, feito pelo homem em movimento, como uma prótese de seu corpo, seja na relação com o entorno. Os trabalhos no campo da arte que se utilizam desse dispositivo, acionados pelas conexões de rede móveis, friccionam necessariamente esses dois espaços. 0 entrecruzamento do âmbito físico e do informático é conceituado pelo autor como "geografias celulares".

Essa definição de geografias celulares nos parece muito adequada para olharmos a malha urbana tecida pelas imagens realizadas com dispositivos móveis sob outro aspecto. A partir dessas imagens da cidade, do cotidiano e da vida social, estamos acrescentando dados à história das cidades, por meio de uma camada maleável, fragmentada, subjetivada de sua imaterialidade cultural. Ou, como diz Bastos: "A cidade vê sua capa imaterial transformada em um elemento de paisagem." (BASTOS, 2010, p.10).

\section{A tela como interface}

A tela como interface expositiva na era da mobilidade e a proliferação de aparelhos conectados a redes sem fio permitem a mediação contínua do usuário e a construção de novas cartografias, novos procedimentos de territorialização e agenciamento (BEIGUELMAN; LA FERLA, 2011). A autora levanta a importância de redimensionarmos a discussão sobre a cultura de rede e o fomento ao consumo, ao controle e ao uso crítico e criativo das mídias existentes.

\section{Essas microtelas são extensões de dispositivos complexos e inteligentes, dotados de conexão à internet e acesso a serviços e redes sociais. Abrem possibilidades inéditas de fomento ao consumo, ao controle e ao uso crítico e criativo das mídias e apontam para diferentes concepções e tendências políticas da ecologia midiática atual. (BEIGUELMAN; LA FERLA, 2011, p.248)}

A autora alerta para a outra face do nomadismo e do uso de dispositivos móveis, centrais no campo da contracultura e das micropolíticas (como vimos com Bourriaud). Destaca a força do marketing, da "brandificação", que se utilizam de estratégias de "domesticação do imaginário" e estão presentes em todos os conteúdos e serviços pelos quais nos comunicamos diariamente (nos celulares, nas plataformas Twitter, Facebook, YouTube, Instagram).

Os territórios informacionais fazem parte do nosso cotidiano e estamos inseridos nesse contexto de brandificação. Torna-se fundamental, portanto, discernirmos entre as imagens publicadas a partir de estratégias de branding e as imagens nas quais nos debruçamos e que nos interessam para essa pesquisa, cuja 
7 HARVEY, David. The Crisis of Planetary Urbanization. Disponível em: <http:// post.at.moma.org/ content_items/520-the-crisisof-planetary-urbanization>. Acesso em: maio 2015. potencialidade poética nos conecta a outras estratégias no campo da arqueologia, da arquitetura, das artes visuais e da net art.

Beiguelman aponta para a problematização do uso controlado e privado dos territórios informacionais, mas enfatiza, com otimismo, o outro lado da moeda, das diversas estratégias que se utilizam dessa rede como lugar de produção, troca, compartilhamento e veiculação de produções artísticas. Trata da relação homem-aparelho celular a partir do pensamento flusseriano sobre fotografia:

O nomadismo contemporâneo vinculado aos dispositivos móveis pode sugerir um processo de criação dentro de cadeias industriais, em que nos tornamos amalgamados aos aparelhos e às suas regras internas, fazendo que seja decisivo o enfrentamento das normas predefinidas no seu programa. (BEIGUELMAN; LA FERLA, 2011, p.234)

Os paradigmas teóricos de Bourriaud, Rancière, Beiguelman e Bastos formam um panorama do contexto e da natureza das narrativas com imagens mobile, oferecendo uma nova perspectiva para estudarmos as novas linguagens de representação e de ressignificação da paisagem urbana, na chave da artemídia. E nos convidam a fazer conexões com conceitos relacionados ao espaço urbano, na chave do urbanismo e da arquitetura.

\section{A rua, rastros e fluxos}

Mover-se é essencial para o conceito da "tecnologia extensiva". O uso do celular depende do corpo para completar sua função móvel, para recriar a figura do caminhante contemporâneo, apreendedor da paisagem urbana e criador de narrativas imagéticas no Instagram.

Em Walkscapes: o caminhar como prática estética, o arquiteto e professor Francesco Careri faz um retrospecto histórico da atividade andarilha desde os povos nômades até os dias de hoje. Para o autor, o ato de caminhar "é um instrumento estético capaz de descrever e modificar os espaços urbanos, preenchidos de significados, de coisas" (CARERI, 2013, p.28). O homem deixa seus rastros, os menires.

0 rastreamento do espaço, marcado pelo homem primitivo com os menires, se assemelha ao rastreamento do espaço do portador de um dispositivo móvel, realizado pela indexação das fotos com pins de localização nos mapas do usuário do Instagram e pelo uso de "\#" (hashtags acrescidas de uma palavrachave). Um "estive aqui", anexado à imagem.

A definição de espaço de David Harvey contribui para o entendimento da evolução do espaço urbano, das cidades, que hoje, na era das redes e da globalização, passaram a ser denominadas territórios metropolitanos. Como visto com Bastos e Beiguelman, o lugar criado pelas redes sociais, como espaço interativo significativo, com diversidade de usos e ampla gama de funções e expressões culturais, mantém e depende de uma interação entre o ambiente físico e o virtual.

Harvey vai enriquecer esse debate reforçando a importância de observarmos as ações sociais sobre o espaço para entendermos o axioma fundamental "tempo e espaço", nas práticas urbanas. Em um artigo escrito para o catálogo da exposição Uneven Growth: Tactical Urbanisms for Expanding Megacities ${ }^{7}$, o 
autor comenta os movimentos sociais e as manifestações de rua, organizados por diversos estratos da população, em uma escala global. Cita como exemplo as manifestações em várias cidades do Brasil contra a tarifa de ônibus, em junho de 2013, e outras manifestações pelo mundo - como as que ocorreram na Turquia, nos Estados Unidos (Occupy Wall Street) e na Espanha (15-M).

Esses acontecimentos coletivos são amplificados pela hipermediação das redes sociais. Eles representam uma nova tendência de comportamento sociocultural, que vai além dos motivos políticos em questão. Há um movimento crescente de ocupar as ruas como o lugar do ponto de encontro, em várias escalas de atuação. A volta do cidadão às ruas tem crescido como parte inerente ao direito do cidadão, que reivindica o espaço público como o lugar da convivência, da troca, e não só como o lugar da mobilidade, do deslocamento. A representação estetizada desses eventos, por meio de milhares de imagens compartilhadas nas redes sociais, cresce na mesma proporção, retroalimentando as manifestações e a partilha do sensível do cidadão participativo.

Já numa escala bem menor, vemos pequenos grupos se organizando para a conservação da praça do bairro, ou para a criação de uma horta coletiva. Em São Paulo, associações como Parque Minhocão e Parque Augusta se articulam politicamente, mobilizando moradores, comerciantes locais e a população em geral por meio de um discurso calcado "no direito à cidade". Outros coletivos entre eles, A Batata Precisa de Você, Casa da Lapa, Coletivo Agulhas, Coletivo BijaRi - vêm atuando na cidade na mesma chave do urbanismo tático citado por Harvey. Esses coletivos oferecem uma possibilidade de ocupação e ressignificação do espaço urbano a partir de ações específicas. Criam-se eventos culturais in loco que são previamente divulgados e amplificados, por meio das imagens mediadas nas redes sociais.

A cidade contemporânea está imbricada com as atuações no campo das artes e com os territórios informacionais. Os movimentos coletivos de ocupação do espaço urbano e a crítica aos modelos de uso desse espaço se dão por meio de ações de diversas naturezas: intervenções, performances, passeatas,

manifestações, imagens e poéticas no espaço territorial e nas redes. Em alguma medida, os cidadãos parecem ter acordado para reivindicar seus direitos básicos, convergindo na busca de uma cidade menos hostil, mais usável, mais móvel e mais compartilhada.

Nota-se uma nova ressignificação da urbes, vivenciada pelos seus habitantes, mais sensíveis e preocupados com o seu locus e o seu entorno. A mobilização coletiva dessa onda de ressignificação e infiltração sociocultural do espaço urbano tomou um rumo inédito com a visibilidade dada a esses eventos nas redes sociais. Os eventos acontecem simultaneamente no local e, por meio de imagens, de forma fragmentada, no Instagram, Facebook, Twitter.

A participação dos cidadãos, com suas câmeras de celulares/dispositivos móveis, nesses acontecimentos nos indica, através dos milhares de posts de imagens desses eventos, como a paisagem da cidade hoje é apreendida por meio de imagens mediadas.

Interessante notar que essas narrativas visuais podem ir além das manifestações poéticas e afetivas de ressignificação da paisagem urbana e dos 
espaços públicos. Essas imagens podem nos fornecer uma infinidade de dados acerca dos modos de usar, repensar e transformar os espaços públicos das cidades contemporâneas.

Parece-nos lógico associar a megaprodução de imagens ao conceito de cidade participativa, na medida em que exemplifica não só a produção de linguagem do homem contemporâneo, mas uma mudança de comportamento do cidadão que passa da vivência interativa para um modo participativo. Os componentes político-social e cultural, tratados por Bourriaud e Rancière, são os ingredientes das manifestações imagéticas e agenciam o potencial poético dessas imagens.

Essas conexões teóricas de campos tão diferentes parecem-nos fundamentais para introduzir e ilustrar a simbiose das narrativas no Instagram com a vida do cidadão na cidade de São Paulo. A produção de linguagem está historicamente ligada aos acontecimentos políticos e socioculturais no espaço urbano. A imagem mobile tem uma matriz essencialmente urbana, nômade e tecnológica. Sua vocação móvel, de circulação em novas geografias celulares, nos apresenta um novo paradigma do momento atual, de ressignificação do ethos do homem contemporâneo.

Essa nova produção de linguagem e representação da paisagem urbana incorpora o território informacional e as redes sociais, como parte inerente da evolução do espaço e, portanto, dos lugares onde habitamos - territórios cíbridos. Ela levanta questões importantes sobre a produção artística do "qualquer um" e nos mostra a nebulosidade entre as fronteiras do individual e do coletivo.

A imageria urbana da rede representa a partilha do sensível da paisagem urbana e uma nova manifestação poética. As imagens \#cicloviapaulista representam apenas uma pequena amostra da potencialidade das imagens nas redes.

\section{REFERÊNCIAS}

BASTOS, Marcus. "Mapeamento incompleto de algumas geografias celulares". In: Geografias Celulares. Catálogo. Espacio Fundación Telefónica: Buenos Aires, 2010, p. 9-18.

BEIGUELMAN, Giselle; LA FERLA, Jorge. Nomadismos tecnológicos. São Paulo: Senac, 2011. $278 \mathrm{p}$

BOURRIAUD, Nicolas. Radicante. Por uma Estética da Globalização. São Paulo: Martins Fontes, 2011. 192 p.

CARERI, Francesco. Walkscapes: o caminhar como prática estética. São Paulo: Gustavo Gili, 2013. $188 \mathrm{p}$.

COUCHOT, Edmond. A tecnologia na arte. Da fotografia à realidade virtual. Porto Alegre: Editora da UFRGS, 2003. 320 p.

HARVEY, David. The Crisis of Planetary Urbanization. Disponível em: <http://post.at.moma.org/ content_items/520-the-crisis-of-planetary-urbanization>. Acesso em: maio 2015.

FOLHA de São Paulo. "Número de smartphones em uso no Brasil chega a 168 milhões, diz estudo". Folha de São Paulo, São Paulo, 15 abril 2016, Mercado. Disponível em: <http:// www1.folha.uol.com.br/mercado/2016/04/1761310-numero-de-smartphones-em-uso-no-brasilchega-a-168-milhoes-diz-estudo.shtml>. Acesso em: junho 2016.

INSTAGRAM. Disponível em: <https://www.instagram.com/about/us/>. Acesso em: outubro 2015. 
JUNIOR, Edgard. Rádio Onu. União Internacional de Telecomunicações. Disponível em: <http:/ /www.ebc.com.br/tecnologia/2015/>. Acesso em: junho 2016.

PRATA, Didiana. Imageria e poéticas de representação da paisagem urbana nas redes.

2016. 220 p. Dissertação (Mestrado em Arquitetura e Urbanismo) - Faculdade de Arquitetura e Urbanismo da Universidade de São Paulo, São Paulo, 2016.

RANCIĖRE, Jacques. A partilha do sensível: estética e política. São Paulo: Editora 34, 2005.

$71 \mathrm{p}$.

RANCIÈRE, Jacques. O destino das imagens. Rio de Janeiro: Contraponto, 2013.151 p.

TELECO. Estatísticas de celulares no Brasil. Disponível em: <http://www.teleco.com.br/ ncel.asp>. Acesso em: junho 2016.

\section{Nota da Autora}

Fonte de imagens: todas as imagens do Instagram foram selecionadas no próprio aplicativo ou pelo Iconosquare, gerenciador de contas vinculado à conta do usuário @didianaprata. As edições foram realizadas a partir dos metadados das imagens (hashtags - palavras-chave, dado de geolocalização e nome do autor) e terão uso restrito à esta pesquisa acadêmcia.

\section{Nota do Editor}

Data de submissão: 22/02/2016

Aprovação: 31/07/2017

Revisão: Silvana Vieira

\section{Didiana Prata}

Faculdade de Arquitetura e Urbanismo. Universidade de São Paulo. São Paulo, SP. didiana@pratadesign.com.br 


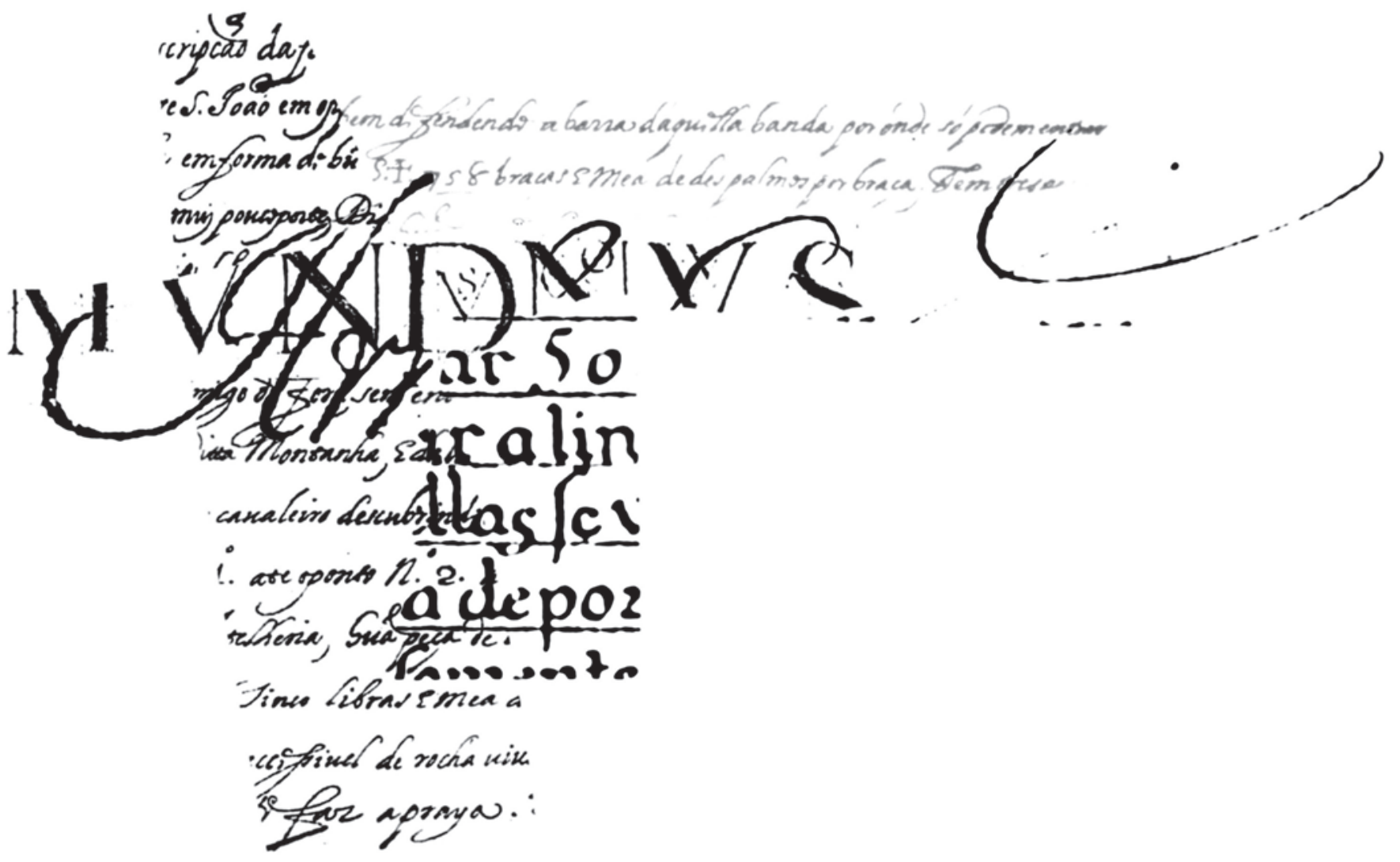

